“ (C) 2017 IEEE. Personal use of this material is permitted. Permission from IEEE must be obtained for all other uses, in any current or future media, including

reprinting/republishing this material for advertising or promotional purposes, creating new collective works, for resale or redistribution to servers or lists, or reuse of any copyrighted component of this work in other works." 


\title{
Connection Stiffness Identification of historic Timber Buildings using
}

\author{
Temperature-based Sensitivity Analysis \\ Mengning Lyu ${ }^{1,2}$, Xinqun Zhu² and Qingshan Yang ${ }^{1}$ \\ ${ }^{1}$ Beijing's Key Laboratory of Structural Wind Engineering and Urban Wind Environment, \\ School of Civil Engineering, Beijing Jiaotong University, Beijing, China. \\ ${ }^{2}$ School of Computing, Engineering and Mathematics, Western Sydney University, Penrith, Sydney, \\ NSW 2751, Australia
}

\begin{abstract}
The beam-column connection, called 'Que Ti', is the key component of historic Tibetan timber buildings to transfer shear, compression and bending loads from one structural element to another. This kind of connections can reduce the internal forces and improve the structure's ability to resist earthquakes. Its structure is very complicated and there is little information about the behaviour of this kind of semi-rigid connections. In this paper, a temperature-based response sensitivity method is proposed to identify the connection stiffness of the 'Que-Ti' in typical historical Tibetan buildings from temperature and strain response measurements. The semi-rigid connection is modelled as two rotational springs and one compressive spring. The temperature is treated as a measureable input and the thermal loading on the structure can be determined from the temperature variation. The numerical results show the method is effective and reliable to identify both unknown boundary conditions and the connection stiffness of the structure accurately even with $10 \%$ noise in measurements. A long-term monitoring system has also been installed in a typical historical Tibetan building and the monitoring data are used to further verify the proposed method. The experimental results show that the identified stiffness by the proposed method are consistent with that by finite element model updating from ambient vibration measurements.
\end{abstract}

Keywords: historic buildings, connection stiffness identification, temperature, response sensitivity 


\section{Introduction}

Historic Tibetan buildings have an important role in the cultural heritage of society. These structures are subjected to earthquake, environmental and operational loading and they have experienced large environmental changes in last few centuries. There is an increasing interest to develop a rigorous and reliable approach for assessing the condition of these historic structures in operational environments. The historic timber architecture is a special kind of frame structures with the unique joint called 'Que-Ti', as shown in Figure 1. 'Que-Ti' is a key component in historic Tibetan timber buildings and it is very important to assess the condition of this joint in the operational environment for structural safety.

During the past decade, many advanced analysis techniques such as finite element method have been applied to describe the various types of connections in the timber structures, e.g., Dou Gong (Fujita et al. 2000; Richard et al. 2004), the mortise and tenon joint (Chang et al. 2004; Brungraber et al. 1985; Sandberg et al. 2000), the plug-slot (King et al. 1996), the glued in rod (Tlustochowicz et al. 2011; Sato et al. 2007) and drift pins (Shojo et al. 2004). To authors' knowledge, there is a little research on modeling of 'Que-Ti'. Bjorhovde et al. (1990) reported that the actual stiffness or restraint of connections lies between the two extremes of pinned and rigid, resulting in the development of connection stiffness models. Semi-rigid connections in frames have attracted attention of the researchers in last decades (Abdalla and Chen 1995; Kim and Chen 1998; Goto and Miyashita 1998; Sekulovic et al. 2002). Particularly, the existence of semi-rigid joints in ancient timber architecture has become significant as it transfers shear, compression, and bending loads from one structural element to another. It can also reduce the internal forces and improve the structure's ability to resist earthquakes (Fang et al. 2001).

Past studies have illustrated the significance of structural identification by using the field measurements to validate and update analytical models (Aktan et al. 1997; Brownjohn et al. 2003). Time histories of dynamic responses were adopted to identify the damage in the structure (Cattarius and Inman 1997). Structural stiffness parameters of a multi-storey framework were identified using the modal response in time domain with the genetic algorithm (Koh et al. 2000). The dynamic response sensitivity based finite element model updating method has been developed to identify structural parameters (Lu and Law 2007; He and Lu 2010; Lu and Liu 2011; Lu et al. 2013). The 
method only needs a few number of measurement points and it still can provide high accuracy for parameter identification as it takes advantage of the plentiful time history data. In fact, structural identification that is based on a reference set of measured data usually has the problem of different environmental temperatures in the two sets of measurements, and the effect of the temperature difference is normally ignored in the subsequent model updating (Wei and Lv 2015). Thermal effect may be more significant as the temperature generated by large ambient temperature variation may be larger than those produced by live load. The temperature effects have been considered in the structural health monitoring (Mata 2011; Yuen and Kuok 2010; Chen et al. 2011). Previous measurements indicate large changes in intrinsic forces over time and the exact mechanisms that give rise to these forces are not known (Catbas and Aktan 2002). The research has revealed that discrepancies in the predicted versus measured responses of a constructed system are typically significant and it often results from an inability to accurately model all of the critical mechanisms in a priori manner. It is important to recognize that such errors are largely independent on any inherent shortcomings of available simulation tools, but rather, reflect a lack of knowledge or epistemic uncertainty (Yarnold et al. 2015).

Recently, a few researchers have tried to identify structural parameters of bridges using the temperature-based approach. Kulprapha and Warnitchai (2012) investigated the feasibility to monitor the structural health of multi-span pre-stressed concrete bridges using the ambient thermal loads and responses, such as strains, deflections and support reaction forces etc. Yarnold and Moon (2015) created the structural health monitoring baseline by utilizing the relationship between temperature changes and the strain/displacement responses. The thermal load is a slow-varying load compared with other dynamic loads. Lyu and Yang (2017) developed a recursive least-squares method to extract the thermal load of a bridge structure from measured acceleration responses.

In this paper, a temperature-based response sensitivity method has been developed to identify the connection stiffness of the semi-rigid joint in typical historic Tibetan buildings from measured strain responses and temperatures. The structural temperature is monitored and then the thermal loading on the structure can be obtained from the temperature variation. This thermal loading is the excitation input of the structural system and the measured strain response is the output of the system. The structural parameters are determined using the temperature-based response sensitivity. 'Que-Ti' is 
modeled as two rotational springs and one compressive spring. A two dimensional frame model is used to address the accuracy and reliability of the proposed method. A long-term monitoring system has been installed in a typical Tibetan heritage building and the collected data has been verified the method. The numerical results show that both unknown boundary conditions and the stiffness of the 'Que-Ti' can be identified accurately in the time domain even with $10 \%$ noise in strain measurements. The identified results from the field monitoring data using the proposed method are consistent with that using the traditional dynamic method from ambient vibration measurements.

\section{Numerical study}

\subsection{Model of the 'Que-Ti'}

One of the unique characteristics for typical Tibetan historic timber structures is the use of the 'Que-Ti' as connections that transfer the loading between beam and column. The shear and bending resistance at the beam end can be improved by an increase in the bearing area at the end of the beam, and a decrease of the beam span. It seldom involves nails or pins in its construction (Fang et al., 2001). The beam-column joint of a historic timber architecture, as shown in Figure 1, is typically a planar structural component supporting column from the top and beams coming in from two horizontal directions with the beam discontinued at the top of the column. The thickened parts of the connecting members close to the intersection form the 'Que-Ti'. With consideration of this arrangement, three linear springs are used to simulate the behaviour of a 'Que-Ti' in which two of them are rotational springs with stiffnesses K2 and K3 to simulate the behaviour of the rotating restraint on the beam, and the other one with stiffness $\mathrm{K} 1$ has vertical compressive stiffness to simulate the compression behaviour perpendicular to grain as shown in Figure 2. In this study, all strain measurements in the time frame are much smaller than $300 \mu \varepsilon$. According to the GB/T 1931-2009 (NSTC, 2009), the behaviour of time materials can be treated as linear elastic when the strain is less than $0.16 \%$ (about $1600 \mu \varepsilon)$. Considering only thermal load was adopted in this study which cause strain are all small and in linear range, the three spring stiffness matrices are assumed linear and uncoupled.

\subsection{A priori finite element model of a timber frame structure in typical Tibetan building}

As shown in Figure 3, a two dimensional frame structure with unknown parameters rotational spring stiffnesses $K_{2}, K_{3}, K_{5}$ and $K_{6}$ and vertical compressive spring stiffnesses $K_{1}$ and $K_{4}$ are adopted to illustrate the approach. This structure is modelled using two planar beam finite elements with three 
internal nodes in the vertical component (simulation of column components), and three planar beam finite elements with 10 internal nodes in the horizontal component. The structure is simply-supported at column bases and sliding-hinged at the end of beams. The cross-section of all beam members is $0.25 \mathrm{~m} \times 0.5 \mathrm{~m}$ and the cross section of column is a variable cross-section from $0.25 \mathrm{~m} \times 0.25 \mathrm{~m}$ to $0.4 \mathrm{~m} \times 0.4 \mathrm{~m}$. Beam and column members are of $4.150 \mathrm{~m}$ and $3.370 \mathrm{~m}$ long respectively. The material properties are assumed to be uniform along the length of the component. The mass density and the elastic modulus of material are $0.418 \mathrm{~g} / \mathrm{cm}^{3}$ and $6435 \mathrm{MPa}$ respectively. No external static loading is considered on the frame other than the self-weight of the structure. This configuration will be adopted for all studies in this paper.

The response data used for this study was generated from a numerical modelling in which a measured temperature time history was applied and the response measurements include the strains at the beam and column. Unknown parameters can be identified using the temperature based response sensitivity analysis as shown below.

\subsection{Temperature-based response sensitivity analysis}

Figure 4 shows the strain measurements via the ambient temperature changes in a typical Tibetan historical building. The information of instrumentation and location of sensors will be mentioned in Section 4.2. Figures 4(a) and 4(c) show strain responses and temperature measurements on the beam over one day and one year, respectively. The measurements on the column over one day and one year are shown in Figures 4(b) and 4(d). The plots show clearly that structural strain responses closely follow the temperature cycle implying that temperature variations play a key role in determining deformations of these components. Figure 4(e) shows the relationship between the temperature and the strain in one year. By the linear regression analysis, the R-squared value is 0.76 and the relationship between the temperature and the strain is approximate linear. In this study, 300 data points are enough to get results as shown in Section 3.3. The temperature versus strain responses can be treated as a approximate linear relationship in this short term period. Based on above, the structural response of a building is approximated a function of temperature and the temperature response is sufficient to enable interpretation of measurements from long-term monitoring.

For a general finite element model of a linear elastic time-invariant system with $n$ elements, the equation of the strain caused by the thermal variation $[\varepsilon]$ is given by 


$$
[\boldsymbol{\varepsilon}]=[\mathbf{B}][\mathbf{K}]^{-1}[\mathbf{F}]
$$

The temperature effect on different elements has been considered in this study. Different thermal loads in different elements can be achieved from enough measurement points and modeling dense mesh. Since the temperature variation is treated as a force function in this study, Eq. (1) can be further rewritten as

$$
\left[\begin{array}{c}
\varepsilon_{i}^{1} \\
\varepsilon_{i}^{2} \\
\vdots \\
\varepsilon_{i}^{m-1} \\
\varepsilon_{i}^{m}
\end{array}\right]=[\mathbf{B}][\mathbf{K}]^{-1}\left[\begin{array}{c}
\alpha_{1} E_{1} A_{1} \Delta T_{i}^{1} \\
\alpha_{2} E_{2} A_{2} \Delta T_{i}^{2} \\
\vdots \\
\alpha_{m-1} E_{m-1} A_{m-1} \Delta T_{i}^{m-1} \\
\alpha_{m} E_{m} A_{m} \Delta T_{i}^{m}
\end{array}\right] \quad(i=1,2 \ldots, n)
$$

where $[\mathbf{B}]$ and $[\mathbf{K}]$ are the system strain-displacement relation matrix and stiffness matrix respectively. $\Delta T_{i}^{j}$ is the temperature variation of the $j$ th element at the ith time step and $\alpha_{j}$ is the material thermal expansion coefficient of the $j$ th element. $E_{j}, A_{j}$ are the modulus of elasticity and the cross sectional area of the $j$ th element. $m$ is the total number of the finite elements for the structure and $n$ is the total time steps.

The difference of responses between measurements and calculations can be obtained as follow,

$$
[\Delta \mathbf{R}]=[\boldsymbol{\varepsilon}]_{c}-[\boldsymbol{\varepsilon}]_{m}=[\mathbf{B}][\mathbf{K}]^{-1}\left[\begin{array}{c}
\alpha_{1} E_{1} A_{1} \Delta T_{i}^{1} \\
\alpha_{2} E_{2} A_{2} \Delta T_{i}^{2} \\
\vdots \\
\alpha_{m-1} E_{m-1} A_{m-1} \Delta T_{i}^{m-1} \\
\alpha_{m} E_{m} A_{m} \Delta T_{i}^{m}
\end{array}\right]-\left[\begin{array}{c}
\varepsilon_{i}^{1} \\
\varepsilon_{i}^{2} \\
\vdots \\
\varepsilon_{i}^{m-1} \\
\varepsilon_{i}^{m}
\end{array}\right]_{m} \quad(i=1,2 \ldots, n)
$$

Differentiating both sides of Equation (2) with respect to the stiffness parameter of the system gives

$$
\frac{\partial[\boldsymbol{\varepsilon}]}{\partial p_{j}}=[\mathbf{B}][\mathbf{K}]^{-1} \frac{\partial[\mathbf{K}]}{\partial p_{j}}[\mathbf{K}]^{-1}\left[\begin{array}{c}
\alpha_{1} E_{1} A_{1} \Delta T_{i}^{1} \\
\alpha_{2} E_{2} A_{2} \Delta T_{i}^{2} \\
\vdots \\
\alpha_{m-1} E_{m-1} A_{m-1} \Delta T_{i}^{m-1} \\
\alpha_{m} E_{m} A_{m} \Delta T_{i}^{m}
\end{array}\right] \quad(i=1,2 \ldots, n)
$$

where $\left\{p_{j}, i=1,2, \cdots m\right\}$ are unknown stiffness parameters.

From Equation (3), the strain residual sensitivity matrix can be obtained as 


$$
S_{j}=\left[\frac{\partial \boldsymbol{\varepsilon}}{\partial p_{j}}\right]=[\mathbf{B}][\mathbf{K}]^{-1} \frac{\partial[\mathbf{K}]}{\partial p_{j}}[\mathbf{K}]^{-1}\left[\begin{array}{c}
\alpha_{1} E_{1} A_{1} \Delta T_{i}^{1} \\
\alpha_{2} E_{2} A_{2} \Delta T_{i}^{2} \\
\vdots \\
\alpha_{m-1} E_{m-1} A_{m-1} \Delta T_{i}^{m-1} \\
\alpha_{m} E_{m} A_{m} \Delta T_{i}^{m}
\end{array}\right]
$$

The length of the sensitivity vectors is the same as the number of measured data points, and the sensitivity vector corresponding to a fractional change of stiffness in the $j$ th element can be rewritten as $S_{j}$. The sensitivity vectors for all structural elements can be computed, and the sensitivity matrix is assembled as

$$
\mathbf{S}=\left[\begin{array}{llll}
\mathbf{S}_{1} & \mathbf{S}_{2} & \cdots & \mathbf{S}_{m}
\end{array}\right]
$$

The identification equation for the stiffness parameters of a structure can be represented as

$$
\left[\begin{array}{ccccc}
\frac{\partial \varepsilon_{1}}{\partial p_{1}} & \frac{\partial \varepsilon_{1}}{\partial p_{2}} & \cdots & \frac{\partial \varepsilon_{1}}{\partial p_{m-1}} & \frac{\partial \varepsilon_{1}}{\partial p_{m}} \\
\frac{\partial \varepsilon_{2}}{\partial p_{1}} & \frac{\partial \varepsilon_{2}}{\partial p_{2}} & \cdots & \frac{\partial \varepsilon_{2}}{\partial p_{m-1}} & \frac{\partial \varepsilon_{2}}{\partial p_{m}} \\
\vdots & \vdots & & \vdots & \vdots \\
\frac{\partial \varepsilon_{n-1}}{\partial p_{1}} & \frac{\partial \varepsilon_{n-1}}{\partial p_{2}} & \cdots & \frac{\partial \varepsilon_{n-1}}{\partial p_{m-1}} & \frac{\partial \varepsilon_{n-1}}{\partial p_{m}} \\
\frac{\partial \varepsilon_{n}}{\partial p_{1}} & \frac{\partial \varepsilon_{n}}{\partial p_{2}} & \cdots & \frac{\partial \varepsilon_{n}}{\partial p_{m-1}} & \frac{\partial \varepsilon_{n}}{\partial p_{m}}
\end{array}\right]\left\{\begin{array}{c}
\Delta p_{1} \\
\Delta p_{2} \\
\Delta p_{m-1} \\
\Delta p_{m}
\end{array}\right\}=\left\{\begin{array}{c}
\Delta R_{1} \\
\Delta R_{2} \\
\Delta R_{n-1} \\
\Delta R_{n}
\end{array}\right\}
$$

or in short

$$
\mathbf{S} \Delta \mathbf{P}=\Delta \mathbf{R}
$$

where $\mathbf{\Delta P}$ is the vector of unknown incremental parameters. Eq. (6) can be solved with an iterative Gauss-Newton method described as below, and the Tikhonov regularization is used the inverse problem by minimising the following objective function in the $k$ th iteration as

$$
\begin{gathered}
P_{k}=P_{k-1}+\left[\mathbf{S}_{k}^{T} \mathbf{S}_{k}\right]^{-1} \mathbf{S}_{k}^{T} \Delta \mathbf{R} \\
J\left(\Delta P_{k}, \lambda_{k}\right)=\left\|\mathbf{S}_{k-1} \Delta P_{k}-\Delta \mathbf{R}\right\|+\lambda_{k}\left\|\Delta P_{k}\right\|^{2}
\end{gathered}
$$

where $\lambda_{k}$ is the regularization parameter in the $k$ th iteration obtained with the $L$-curve method (Hansen, 1992), $\mathbf{S}_{k-1}$ is the sensitivity matrix with the structural model updated by $P_{k}$.

The structural stiffness matrix is updated after $\Delta P_{k}$ is obtained. Then the structural responses and the sensitivity matrix can be re-calculated based on the updated stiffness matrix, and the vector $\Delta P_{k}$ for the next iteration is calculated until the convergence is achieved with the following criterion as 


$$
\frac{\left\|P_{k+1}-P_{k}\right\|}{P_{k}}<\text { Tol }
$$

The value of $\mathrm{Tol}$ is selected to allow for the difficulty in the convergence of the identified results with noise effect. Based on this method, the estimated parameter can be obtained.

\subsection{Numerical results and parametric analysis}

A uniform temperature time history with the $5^{\circ} \mathrm{C}$ temperature increment is applied on the structure as shown in Figure 5. This data is based on the field monitoring data of the traditional building in Tibet and 100 data points are used in this simulation. The strain responses of the structure are calculated as the "measured" responses for the parameter identification, and only two measurements are used in this study, as shown in Figure 6. One strain measurement is on the beam and another one is on the column.

In this study, the stiffness parameters are set as $\mathrm{K}_{1}=1.08 \times 10^{5} \mathrm{kN} / \mathrm{m}, \mathrm{K}_{2}=7700 \mathrm{kNm} / \mathrm{r}, \mathrm{K}_{3}=6300 \mathrm{kNm} / \mathrm{r}$, $\mathrm{K}_{4}=0.92 \times 10^{5} \mathrm{kN} / \mathrm{m}, \mathrm{K}_{5}=7420 \mathrm{kNm} / \mathrm{r}, \mathrm{K}_{6}=6580 \mathrm{kNm} / \mathrm{r}$ respectively. In the identification, the stiffness initial values are set as: $\mathrm{K}_{1}=\mathrm{K}_{4}=1 \times 10^{5} \mathrm{kN} / \mathrm{m}, \mathrm{K}_{2}=\mathrm{K}_{3}=\mathrm{K}_{5}=\mathrm{K}_{6}=7000 \mathrm{kNm} / \mathrm{r}$ which values based on summarized results of semi-rigid connection testing (Leichti et al. 2000). Using the response sensitivity-based method to identify the stiffness $\mathrm{K}_{1}$ to $\mathrm{K}_{6}$ and the accuracy of the identified results are computed from Eq. (10). This configuration will be adopted for all the studies in this work.

$$
\text { Accuracy index }=\frac{K_{\text {identified }}}{K_{\text {real }}} \times 100 \%
$$

where $K_{\text {real }}$ is the true value of the stiffness and $K_{\text {identified }}$ is the identified stiffness.

\subsection{Identified results from strain measurements without or with noise}

The effectiveness of the proposed method is studied with the "measured" responses without noise firstly, and the convergence criterion $\mathrm{Tol}$ is set as $10^{-9}$ in this case. The identification results from the proposed method are shown in Figure 7. The identified results are very close to the true values. The results show that parameters of the semi-rigid connections can be identified accurately from measurements without noise.

In order to study the effectiveness of the proposed method in practice, the measured response is simulated by adding a random noise to the calculated response as 


$$
\varepsilon_{m}=\varepsilon_{c}+E_{p} \sigma\left(\varepsilon_{c}\right) N_{\text {noise }}
$$

where $\varepsilon_{c}$ is the calculated response; $\mathrm{E}_{\mathrm{p}}$ is the noise level; $\sigma\left(\varepsilon_{c}\right)$ is the standard deviation of the unpolluted strain response and $\mathbf{N}_{\text {noise }}$ is a standard normally distributed vector with the zero mean and the unit standard deviation.

$10 \%$ noise level is added to simulate response measurements and the proposed method is used to identify the parameters of the semi-rigid connection. The convergence tolerance is set as $10^{-5}$ and the identification results are shown in Figure 7. From Figure 7, the identification results are agreed well with the true values from measurements with $10 \%$ noise.

\section{Parametric analysis}

Similar to the work by Yarnold et al. (2015), the temperature changes can be treated as a measurable input of the structural system and then a complete input-output relationship of the system can be obtained. To further verify the proposed identification method, the effects of the initial value setting, the temperature difference, the length of the data and the sensor placement adequately have been studied.

\subsection{Effect of the initial value setting}

The stiffness value setting in FEM is according to summarized results of semi-rigid connection testing. In order to study the effect of the initial value on the identified results, three different levels of initial values are set which are $90 \%, 80 \%$ and $50 \%$ of the ideal stiffness value in FEM respectively. The results are shown in Figure 8. The results show that both identified results with the initial values of $90 \%$ and $80 \%$ ideal value are identified accurately, and the one with $90 \%$ of ideal value is more accurate. However, the criterion Tol cannot be achieved after more than 300 iterations with the initial values of $50 \%$ ideal value.

\subsection{Identification with different temperature changes}

The three different temperature curves with $5^{\circ} \mathrm{C}, 15^{\circ} \mathrm{C}$ and $25^{\circ} \mathrm{C}$ increments are shown in Figure 9. The error in the identified results is defined as follows,

$$
\text { Error }=\frac{\left|K_{\text {identified }}-K_{\text {real }}\right|}{K_{\text {real }}} \times 100 \%
$$

Table 1 shows the errors in the identified results with the temperature changes $5^{\circ} \mathrm{C}, 15^{\circ} \mathrm{C}$ and $25^{\circ} \mathrm{C}$. The measurements with $10 \%$ noise are used in this study. The results show that errors in the identified 
results with the temperature changes $15^{\circ} \mathrm{C}$ and $25^{\circ} \mathrm{C}$ are much less than that with the temperature change $5^{\circ} \mathrm{C}$, and all results are quite close to the true values. This is due to the great temperature change will induce the higher thermal loading and the larger strain responses. It can be concluded that the great temperature variation is more suitable for structural parameter identification and in practice at least $15^{\circ} \mathrm{C}$ change in the temperature history curve should be considered.

\subsection{Effect of the data length}

There are four different data lengths adopted in this study, 300, 200100 and 50 data points respectively, as shown in Figure 10. Table 2 shows errors in the identified results with 50, 100, 200 and 300 data points. From the results, the errors in identified results using 200 and 300 data points are much smaller than that using 50 and 100 data points. The error in the identified results is reduced with the number of data points increases. Based on above, when it comes to the application study, at least 100 data points are required.

\subsection{Sensor placements}

Figure 11 shows four different sensor arrangements as Scenarios I, II, III and IV. Scenario I as the full sensor placement scenario has five sensors and other scenarios have only two sensors. The errors in the identified results upon four different kinds of sensor placements with 100 -point data and the $5^{\circ} \mathrm{C}$ temperature increment are shown in Table 3. The errors in the identified results from Scenario I are much less than that from other three scenarios. There is no big difference whether the two sensors are arranged in the middle span of the beam and column or in the one side of the structure while the results would be better in Scenario II.

\subsection{Identification with unknown boundary conditions}

Some traditional timber structures are surrounded by brick enclosure walls which can be seen in Figure 11. However, these walls actually carry the vertical and rotational loads. The information about its restraint for the longitudinal load is less as there are always gaps between the timber frames and walls. Considering the unknown longitudinal boundary condition, which can be treated as a semi-rigid connection and that only contains the longitudinal compressive stiffness. In this case, the end part of the beam inserted into walls can be studied as a pile and the boundary condition can be simplified as the friction between the soil and the pile, whose stiffness can be assumed as Winkler springs (Salgado, 2008). Thus, unknown parameters $K_{7}$ and $K_{8}$ (boundary stiffness) are adopted besides $K_{1}$ to $K_{6}$ as shown in Figure 12 . In addition, set $K_{7}=K_{8}=4.025 \times 10^{4} \mathrm{kN} / \mathrm{m}$ and their initial values are set as $\mathrm{K}_{7}=\mathrm{K}_{8}=3.5 \times 10^{4} \mathrm{kN} / \mathrm{m}$ based on pile stiffness identification results (Kutera and Kacprzak, 2013; Finn, 2004). The results show the boundary conditions can be identified together 
with connection stiffness as shown in Figure 13. The errors in the identified results are 8.07\%, 8.22\%, $5.23 \% 7.23 \%, 6.44 \%, 6.60 \%, 6.27 \%$ and $5.87 \%$ for stiffnesses $\mathrm{K}_{1}$ to $\mathrm{K}_{8}$ respectively.

\section{Experimental studies on a typical Tibetan building}

\subsection{Finite element model of Tibetan heritage timber architectures}

The Tibetan heritage timber architecture adopted in this study is shown in Figure 14. To set up the computational model for traditional timber structures, a 3-storey two dimensional frame (A-A in Figure 15) is taken as a case study. The details are shown in Figures 15 and 16, and the longitudinal boundary condition is treated as a semi-rigid connection with the longitudinal compressive stiffness only. It is assumed that there is no change in the mass and the damping when the temperature in the structure changes. The quality of the floor slab and the roof is treated as the mass element added into the frame structure, whose gravity density is $20 \mathrm{kN} / \mathrm{m}^{3}$, the thickness are $200 \mathrm{~mm}$ and $300 \mathrm{~mm}$ respectively. A priori finite element model is developed and it includes 24 planar beam finite elements with three internal nodes in the vertical column component, 27 planar beam finite elements with 10 internal nodes in the horizontal beam component, 48 rotational spring elements, 24 vertical spring elements and six longitudinal spring elements. Based on the long-term monitoring data (Dai et al., 2016), less than $3 \%$ of total strain are caused by other dynamic loads such as crowded loading and wind loading. The low-pass filter has also been used to remove the high-frequency components due to other dynamic loads. The temperature load is the only excitation considered in this study.

\subsection{Data acquisition system}

According to the on-site measurement of the frame, the strain data was collected at ten measurement points in the frame, as shown in Figure 16. The Fiber Bragg grating strain gauge (FBG) from China Orient Institute of Noise and Vibration is used in this study, as shown in Figure 17. The model of the data acquisition system is BGK-FBG-8600 with 16 channels, as shown in Figure 18. The structure is monitored continuously and the data is collected per hour with the average of six measurements by 10 minutes each. Over three years monitoring data are available from the traditional building monitoring system, which provides a most unique opportunity for development of a reliable evaluation approach.

\subsection{Data processing and interpretation}

In addition to utilize the acquired data for model updating, it is important that the field measurements 
adequately characterize the temperature-induced input-output relationships. Both the strain and temperature information are obtained by using the FBG strain gauge. Based on the numerical studies results, responses induced by a big temperature change is essential for reliably evaluating the structure behavior. The selected data is collected periodically once per week at a specific time. Taking the data from one sensor for example, the strain and temperature time history curves are shown in Figure 19. The temperature variation is treated as a measured force function in this study and then the complete input (temperature) -output (strains) relationship can be established. The relationships are simulated numerically and structural parameters are identified by comparing the calculated responses with the observed responses.

For comparison purposes, the parameter identification based on ambient vibration measurements was also carried out. In July 2012, an ambient vibration test was carried out using three accelerometers and the location can be seen in Figure 20. The accelerometers are of model KD1300C from YangZhou KeDong. The data acquisition system is of model INV3060A from the China Orient Institute of Noise and Vibration with 16 channels. The measuring duration lasts for half hour during the midnight to ensure the structure under the ambient vibration. The sampling frequency is selected at $512 \mathrm{~Hz}$. The natural frequencies and modal assurance criterion (MAC) values are adopted for finite element model updating. The objective function is provided below

$$
\text { Obj Fcn }=\sum_{i=1}^{n}\left\{100\left(\frac{\left|f_{\exp }(i)-f_{a n}(i)\right|}{f_{\exp }(i)}\right)+100\left(1-\frac{\phi_{a n}^{T}(i) \phi_{\exp }(i)}{\left(\phi_{a n}^{T}(i) \phi_{a n}(i)\right)\left(\phi_{\exp }^{T}(i) \phi_{\exp }(i)\right)}\right)\right\}
$$

where $f_{\exp }$ and $f_{a n}$ are the experimental and analytical frequencies respectively. $\phi_{\exp }$ and $\phi_{a n}$ are the experimental and analytical modes shapes respectively.

The calculated results from the ambient vibration based structural identification (AVSI) method are shown in Table 4. MAC values were between $93 \%$ to $98 \%$ and the experimental and analytical frequencies are quite close, which presents AVSI can correct finite element model well. Based on above, the results obtained by AVSI can be used to compare with those obtained from the Temperature-based sensitivity analysis method.

The structure identification results from both temperature-based method and ambient vibration method are presented below. The location and element number of the identified stiffness parameters 
of 48 rotational spring elements, 24 vertical spring elements and six longitudinal spring elements can be seen in Figure 21, and the identification results are shown in Figures 22, 23 and 24. From Figure 22, the identified rotational stiffness is from $3395 \mathrm{kNm} / \mathrm{r}$ to $9147 \mathrm{kNm} / \mathrm{r}$ and its average value is 6324 $\mathrm{kNm} / \mathrm{r}$. In Figure 23, the identified vertical compressive stiffness is from $74186 \mathrm{kN} / \mathrm{m}$ to 121486 $\mathrm{kN} / \mathrm{m}$ and its average value is $93636 \mathrm{kN} / \mathrm{m}$. In Figure 24, the identified longitudinal compressive stiffness is from $24164 \mathrm{kN} / \mathrm{m}$ to $37250 \mathrm{kN} / \mathrm{m}$ and its average value is $31002 \mathrm{kN} / \mathrm{m}$. The average difference between these two methods is less than $10 \%$ while the difference are $22.8 \%, 14.9 \%, 27.6 \%$, $17.7 \%, 26.4 \%, 24.0 \%, 19.4 \%$, and $20.8 \%$ in the $6^{\text {th }}, 9^{\text {th }}, 13^{\text {th }}, 23^{\text {rd }}, 36^{\text {th }}, 37^{\text {th }}, 38^{\text {th }}$ and $44^{\text {th }}$ rotational spring elements respectively, the difference are 14.9\%, 20.7\%, 16.7\% 15.9\%, 18.9\%, 22.4\%, 29.3\%, $21.0 \%$ and $26.7 \%$ in the $1^{\text {st }}, 3^{\text {rd }}, 10^{\text {th }}, 11^{\text {th }}, 14^{\text {th }}, 17^{\text {th }}, 18^{\text {th }}, 19^{\text {th }}$ and $23^{\text {rd }}$ vertical spring elements respectively, and the difference are $16.0 \%$ and $12.6 \%$ in the $3^{\text {rd }}$ and $6^{\text {th }}$ longitudinal spring elements respectively. The reason for the difference is the damping in timber structures which caused by the friction between the components and the special connection mode of joint. The damping is hard to be defined in ambient vibration calculation. Another reason is that the long distance affects the identification accuracy as the spots with large differences are all far away from the location of sensors especially for those spots in the third floor.

In Figure 22, the identified results reflect that the 'Que-Ti' connections are similar but some stiffness values at both sides are quite different. For example, those two rotational stiffness for Elements 27 and 28 do not have similar spring constants. As mentioned in Section 1, the beam in the 'Que-Ti' is not a continuous beam. Both sides of the connection are independent. For Elements 27 and 28, there is an obvious damage happened in the right beam but the left one is good as shown in Figure 25(a). This is agreed well with the identified results. Figure 25(b) shows a beam in the 'Que-Ti' replaced with a new one and Element 53 is related to the compressive spring at this connection. The identified compressive stiffness at Element 53 is much high compared with others as shown in Figure 23.

\section{Conclusions}

A temperature based response sensitivity method has been developed to identify the connection stiffness of the semi-rigid joint in timber buildings from ambient strain and temperature measurements. Numerical and experimental results show that the proposed method is effective and reliable to predict the stiffness of the 'Que-Ti' in typical historic Tibetan timber buildings. The 
following specific conclusions and recommendations can be drawn from this study,

1) The numerical results show that the proposed method is robust to the measurement noise. Even with $10 \%$ noise in the measurements, the identified results are agreed well with the true values.

2) The great temperature change can obtain a better accuracy in the identified results as the larger temperature change induces the higher thermal loading. In practice, at least $15^{\circ} \mathrm{C}$ change in the temperature time history should be used in the identification. Also sufficient data points are needed to get the accurate results in the identification.

3) The boundary condition and the connection stiffness can be identified simultaneously.

\section{Acknowledgments}

The work described in this paper was supported by National Natural Science Foundation of China on Grant 51338001 and 51422801, and Fundamental Research Funds for the Central Universities on Grant C15JB00191. The financial support of the Chinese Government Scholarship was also acknowledged.

\section{References}

Abdalla, K. M. and Chen, W. F. (1995). "Expanded database of semi-rigid steel connections." Computers \& Structures, 56(4), 553-564.

Ali, J. S, Gupta, S. and Bagchi, S. (2013). "Structural damage identification of truss from simple static test data by sensitivity analysis." Proceedings of the Indian Conference on Applied Mechanics, 2013IIT Madras.

Aktan, A. E., Farhey, D.N., Heimicki, A.J., Brown, D.L., Hunt, V.J., Lee, H.-L. and Levi, A. (1997). "Structural identification for condition assessment: experimental arts." Journal of Structural Engineering, ASCE, 123(12), 1674-1684.

Bjorhovde, R., Colson, A. and Brozzetti, J. (1990). "Classification system for beam-to-column connections.” Journal of Structural Engineering, ASCE, 116(11), 3059-3076.

Brownjohn, J., Moyo, P., Omenzetter, P., and Lu, Y. (2003). “Assessment of highway bridge upgrading by dynamic testing and finite-element model updating.” Journal of Bridge Engineering, ASCE, 8(3), 162-172.

Brungraber, R. L. (1985). Traditional Timber Joinery: A Modern Analysis. Ph.D. thesis, Stanford Univ., Palo Alto, Calif.

Catbas, F. N. and Aktan, A. E. (2002). "Condition and damage assessment: Issues and some promising indices.” Journal of Structural Engineering, ASCE, 128(8), 1026-1036 
Cattarius, J. and Inman, D. J. (1997). “Time domain analysis for damage detection in smart structures.” Mechanical Systems ad Signal processing, 11, 409-423.

Chang, W., Hsu, M. and Chen, C. (2004). "Estimating rotational stiffness of timber joints by using fractional factorial experiments combined with computer simulation.” Proceedings of the 8th World Conf. on Timber Engineering, Lahti, Finland, vol. 2, 101-106.

Dai L., Yang N., Zhang L., Yang Q.S. and Law S.S. (2016) "Monitoring crowd load effect on typical ancient Tibetan building" Structural Control and Health Monitoring, 23, 998-1014.

Fang, D. P., Iwasaki, S., Yu, M. H. and Shen, Q. P. (2001). “Ancient Chinese timber architecture. II: dynamic characteristics.” Journal of Structural Engineering, ASCE, 127(11), 1358-1364.

Finn, W.D.(2004). "Characterizing pile foundations for evaluation of performance based seismic design of critical lifeline structures.” Proceedings of the 13th World Conference on Earthquake Engineering Vancouver, B.C., Canada.

Fujita, K., Kimura, M., Ohashi, Y. and Sakamoto, I. (2000). "Static and dynamic loading tests of bracket complexes used in traditional timber structures in Japan." Proceeding of the 12th World Conference on Earthquake Engineering, 2000.

Goto, Y. and Miyashita, S. (1998). "Classification system for rigid and semi-rigid connection." Journal of Structural Engineering, ASCE, 124(7), 750-757.

He, Z. Y. and Lu, Z. R. (2010). “Time domain identification of multiple cracks in a beam.” Structural Engineering and Mechanics, 42, 13-24.

Kim, Y. and Chen, W. F. (1997). "Practical Analysis for Partially Restrained Frame Design”, Journal of Structural Engineering, ASCE, 124(7), 736-749.

King, W. S., Yen, J. Y., and Yen, Y. N. (1996). “Joint characteristics of traditional Chinese wooden frames.” Engineering Structures, 18(8), 635-644.

Koh, C. G., Hong, B. and Liaw, C. Y. (2000). "Parameter identification of large structural systems in time domain.” Journal of Structural Engineering, ASCE, 126, 957-963.

Kulprapha, N. and Warnitchai, P. (2012) "Structrual health monitoring of continuous prestressed concrete bridges using ambient thermal responses.” Engineering Structures, 40, 20-38.

Kutera, B. and Kacprzak, G. (2013). “The pile stiffness in a piled-raft foundation.” Technical transactions: Civil engineering. 2013.2-B.

Leichti, R. J., Hyde, R. A., French , M. L. and Camillos, S. G.(2000). “The continuum of connection rigidity in timber structures.” Wood and Fiber Science, 32(1), 11-19.

Lu, X. B., Liu, J. K. and Lu, Z. R. (2013), “A two-step approach for crack identification in beam.” Journal of Sound and Vibration, 332(2), 282-293.

Lu, Z. R. and Law, S. S. (2007). "Features of dynamic response sensitivity and its application in damage detection.” Journal of Sound and Vibration, 303, 305-329.

Lu, Z. R. and Liu, J. K. (2011). "Identification of both damages and parameters of vehicles for 
bridge-vehicle system from measured dynamic responses.” Computers \& Structures, 89, 1397-1405.

Lyu, M.N. and Yang, Q.S.(2017). "Estimation of Thermal Load in Structural Members from Measured Accelerations.” International Journal of Structural Stability and Dynamics,17(3), http://dx.doi.org/10.1142/S0219455417500365.

National Standardization Technical Committee of China (NSTC) (2009) Mechanical Testing and Properties of Timber Materials (GB/T 1931-2009). China Standards Press, Beijing.

Richard, N., Daudeville, L. and Yasumura, M. (2004). "Seismic response of timber frame structures: experiment and finite element modeling." Proceedings of 8th World Conference on Timber Engineering, Lahti, Finland, vol. 2, 2004; 389-394.

Salgado R. (2008) The Engineering of Foundations, McGraw-Hill, New York.

Sanayei, M. and Imbaro, G. R. (1997). "Structural model updating using experimental static measurements.” Journal of Structural Engineering, ASCE, 6, 12655.

Sandberg, L. B., Bulleit, W. M. and Reid, E. H. (2000). "Strength and stiffness of oak pegs in traditional timber-frame joints.” Journal of Structural Engineering, ASCE, 126(6), 21620.

Sato, M., Isoda, H. and Sugaya, Y. (2007). "Experimental study for timber based semi-rigid frame with bolt and bond.” Architectural Institute of Japan, Journal of Technology and Design, 13(26), 539-544 (in Japanese)

Sekulovic, M., Salatic, R. and Nefovska, M. (2002). "Dynamic analysis of steel frames with flexible connections.” Computers \& Structures, 80(11), 935-955.

Shojo, N., et al. (2004). "Study on the beam-column joint of timber frame structures using drift pins." Journal of Structural and Construction Engineering, 578, 91-97 (in Japanese)

Tlustochowicz, G., Serrano, E. and Steiger, R. (2011). "State-of-the-art review on timber connections with glued-in steel rods.” Materials and Structures, 44(5), 997-1020

Wei, J.J. and Lv, Z.R.(2015). "Structural damage detection including the temperature difference based on response sensitivity analysis.” Structural Engineering and Mechanics, 53(2), 249-260.

Yarnold, M.T. and Moon, F.L. (2015) "Temperature-based structural health monitoring baseline for long-span bridges.” Engineering Structures, 86, 157-167.

Yarnold, M. T.; Moon, F. L. and Aktan, A. E. (2015). “Temperature-Based Structural Identification of Long-Span Bridges.” Journal of Structural Engineering, ASCE, 04015027-1 
Table 1 - Errors (\%) in the identification results with different temperature ranges

\begin{tabular}{|c|c|c|c|}
\hline $\begin{array}{c}\text { Parameter } \\
\text { number }\end{array}$ & $\begin{array}{l}5^{\circ} \mathrm{C} \text { difference in } \\
\text { temperature (\%) }\end{array}$ & $\begin{array}{l}15^{\circ} \mathrm{C} \text { difference in } \\
\text { temperature (\%) }\end{array}$ & $\begin{array}{l}25^{\circ} \mathrm{C} \text { difference in } \\
\text { temperature (\%) }\end{array}$ \\
\hline $\mathrm{K}_{1}$ & 8.00 & 1.55 & 0.72 \\
\hline $\mathrm{K}_{2}$ & 8.20 & 4.44 & 2.40 \\
\hline $\mathrm{K}_{3}$ & 5.20 & 1.98 & 0.72 \\
\hline $\mathrm{K}_{4}$ & 7.15 & 3.60 & 2.04 \\
\hline $\mathrm{K}_{5}$ & 6.38 & 2.98 & 1.62 \\
\hline $\mathrm{K}_{6}$ & 6.55 & 2.50 & 1.53 \\
\hline
\end{tabular}

Table 2 - Errors (\%) in the parameter identification results with different data points

\begin{tabular}{ccccc}
\hline $\begin{array}{c}\text { Parameter } \\
\text { number }\end{array}$ & $\begin{array}{c}\text { 50-point data } \\
(\%)\end{array}$ & $\begin{array}{r}\text { 100-point data } \\
(\%)\end{array}$ & $\begin{array}{c}\text { 200-point data } \\
(\%)\end{array}$ & $\begin{array}{c}300 \text {-point data } \\
(\%)\end{array}$ \\
\hline $\mathrm{K}_{1}$ & 11.75 & 8.00 & 5.88 & 5.50 \\
$\mathrm{~K}_{2}$ & 12.20 & 8.20 & 6.10 & 5.83 \\
$\mathrm{~K}_{3}$ & 10.20 & 5.20 & 4.30 & 3.82 \\
$\mathrm{~K}_{4}$ & 7.52 & 7.15 & 5.65 & 5.41 \\
$\mathrm{~K}_{5}$ & 7.71 & 6.38 & 5.55 & 5.07 \\
$\mathrm{~K}_{6}$ & 7.21 & 6.55 & 5.38 & 5.05 \\
\hline
\end{tabular}

Table 3 - Errors (\%) in the parameter identification results with different sensor locations

\begin{tabular}{ccccc}
\hline $\begin{array}{c}\text { Parameter } \\
\text { number }\end{array}$ & Scenario I (\%) & Scenario II (\%) & Scenario III (\%) & Scenario IV (\%) \\
\hline $\mathrm{K}_{1}$ & 1.81 & 8.00 & 8.29 & 10.16 \\
$\mathrm{~K}_{2}$ & 3.15 & 8.20 & 6.60 & 8.39 \\
$\mathrm{~K}_{3}$ & 2.85 & 5.20 & 4.93 & 5.51 \\
$\mathrm{~K}_{4}$ & 2.50 & 7.15 & 6.89 & 7.80 \\
$\mathrm{~K}_{5}$ & 1.21 & 6.38 & 7.05 & 7.73 \\
$\mathrm{~K}_{6}$ & 0.97 & 6.55 & 6.98 & 7.03 \\
\hline
\end{tabular}


Table 4 - Comparison between experimental and analytical results

\begin{tabular}{llll}
\hline Order & $f_{\exp }(\mathrm{Hz})$ & $f_{a n}(\mathrm{~Hz})$ & MAC(\%) \\
\hline 1 & 9.49 & 9.55 & $97.8 \%$ \\
2 & 15.55 & 15.61 & $94.3 \%$ \\
3 & 19.83 & 19.91 & $93.6 \%$ \\
\hline
\end{tabular}



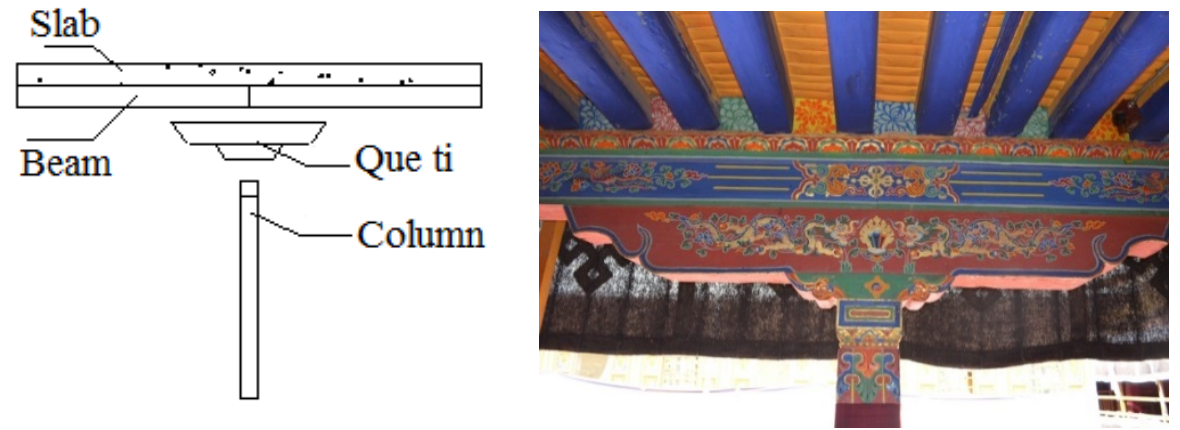

Figure 1 Composition of beam-column joints

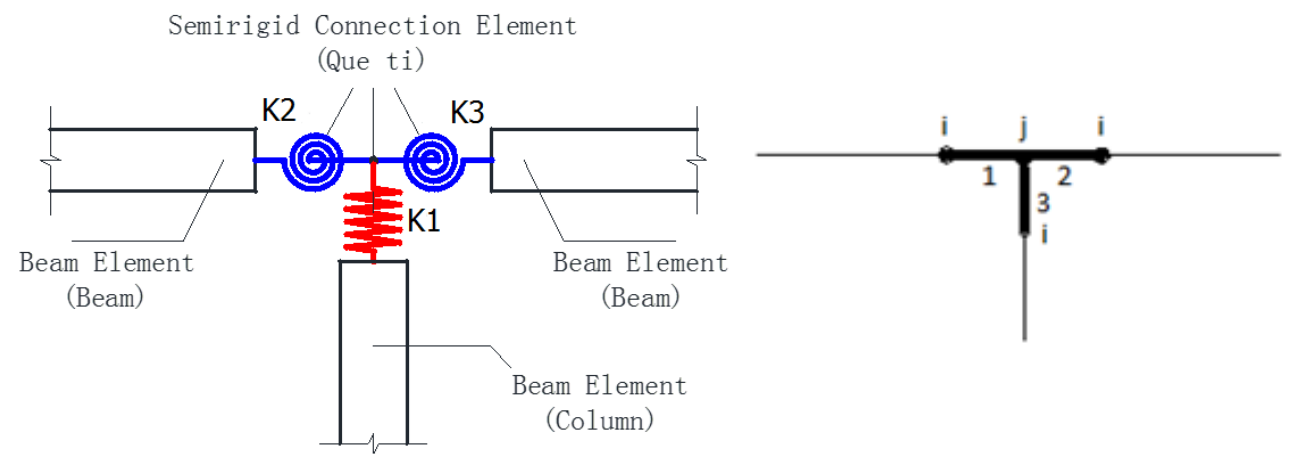

Figure 2 Simplified model of the beam-column connection

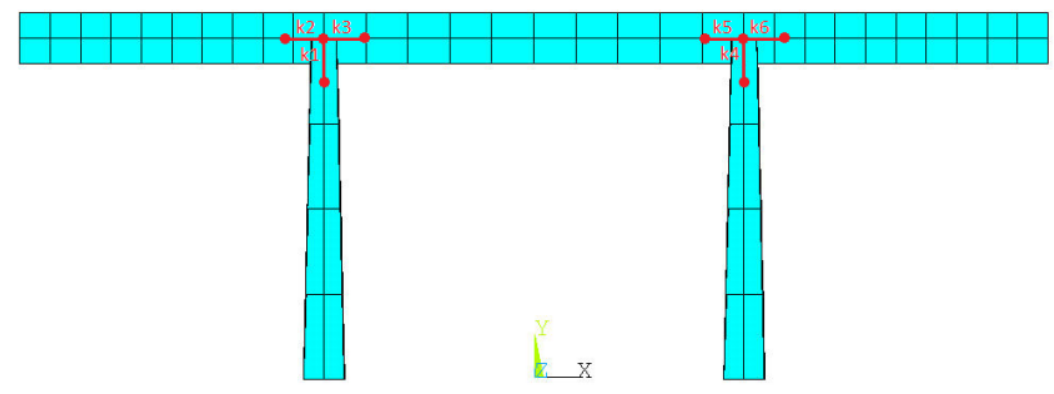

Figure 3 A two dimensional frame structure 


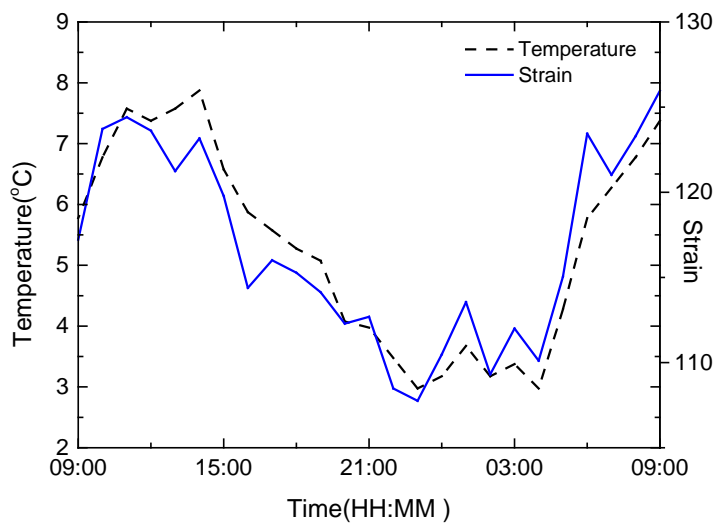

(a) Strain and temperature on the beam over 1 day

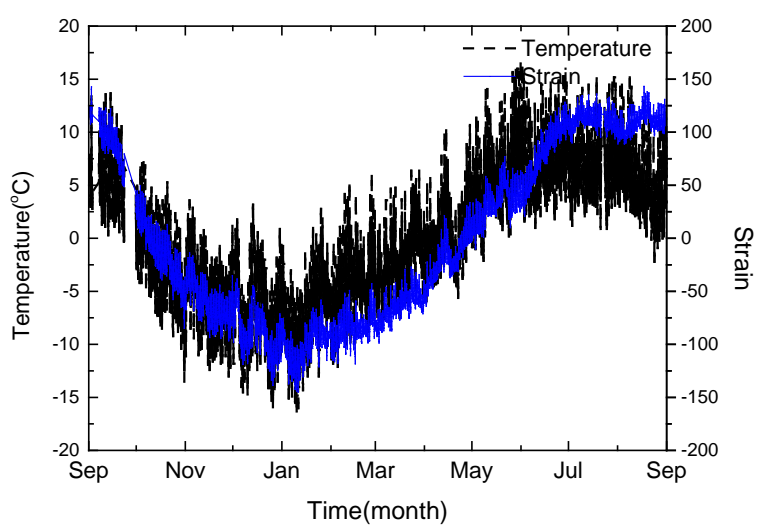

(c) Strain and temperature on the beam over 1 year

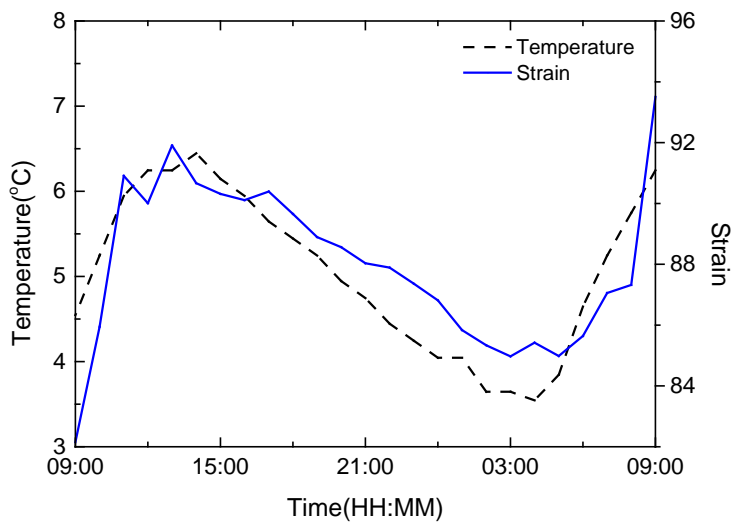

(b) Strain and temperature on the column over 1 day

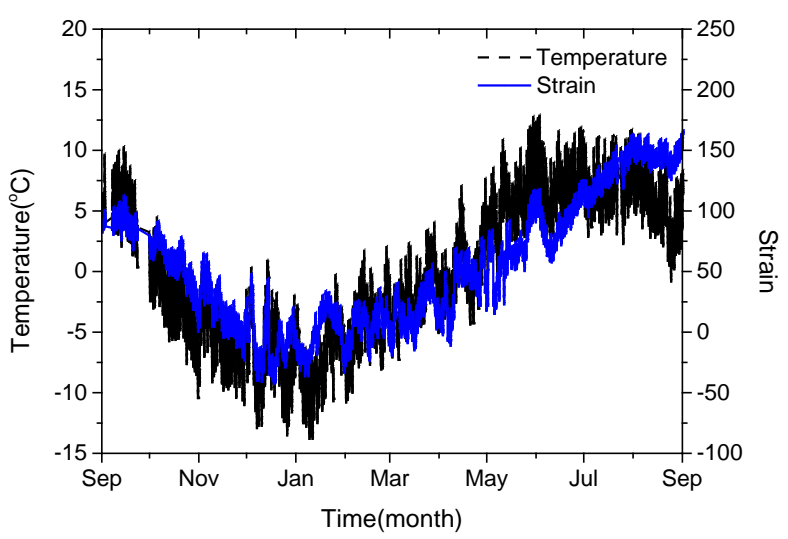

(d) Strain and temperature on the column over 1 year

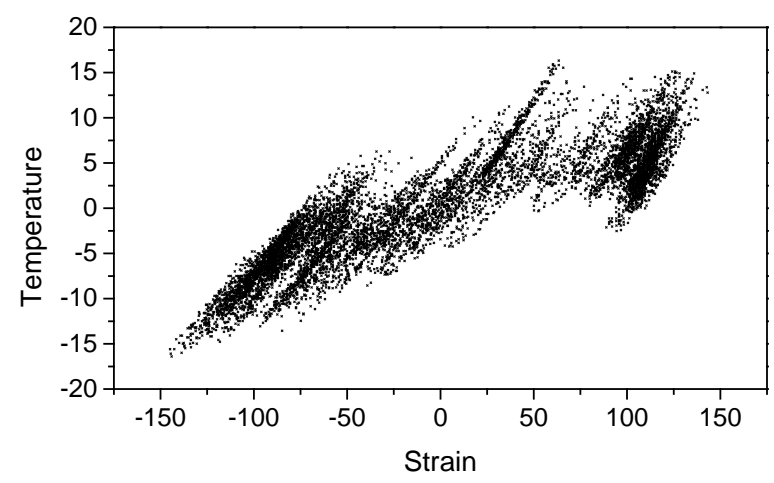

(e) The relationship of temperature versus strain response

Figure 4 Strain measurements from the ancient building in relation to ambient temperature

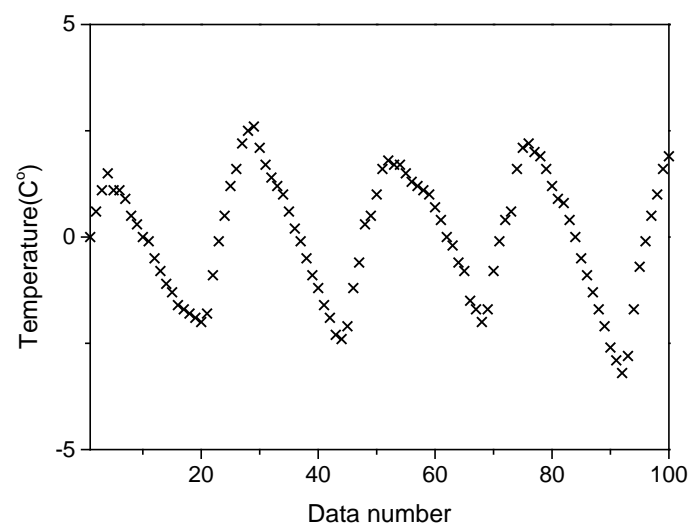

Figure 5 Temperature time history

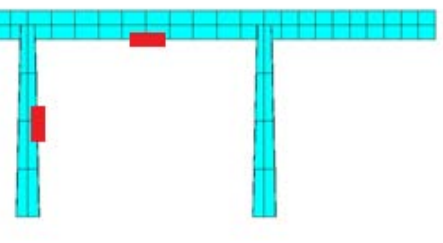

Figure 6 Sensor arrangement 


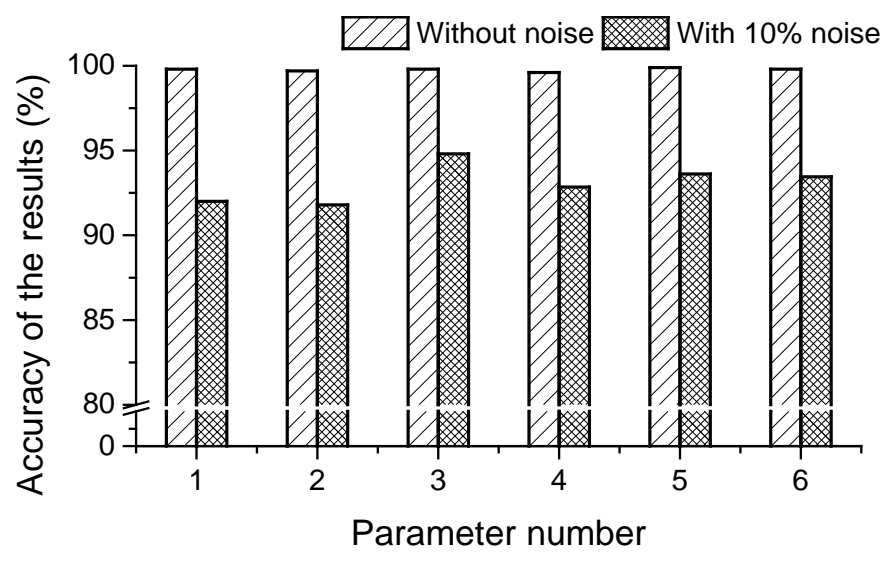

Figure 7 Identified results from measurements with or without noise

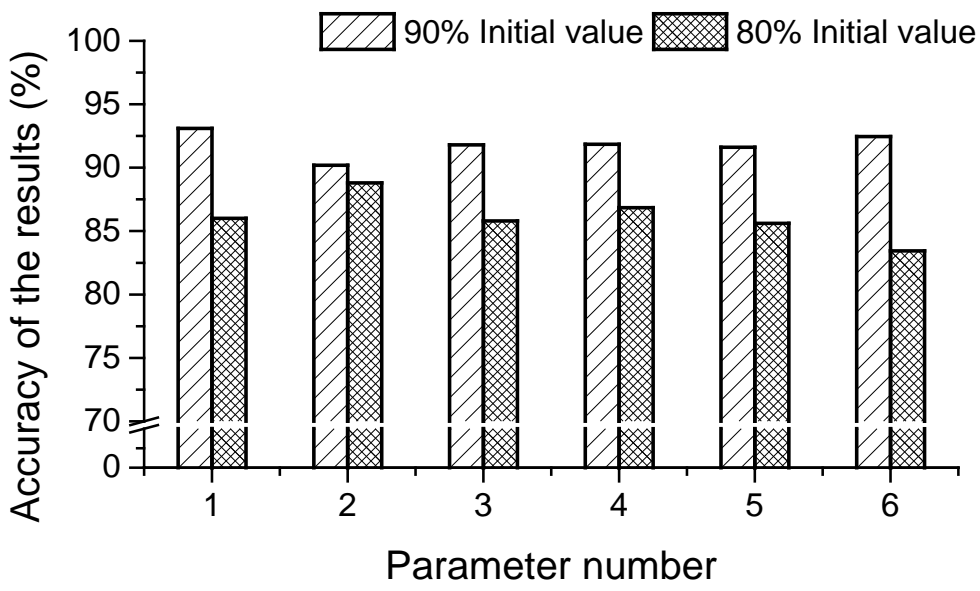

Figure 8 Identified results with different initial values 


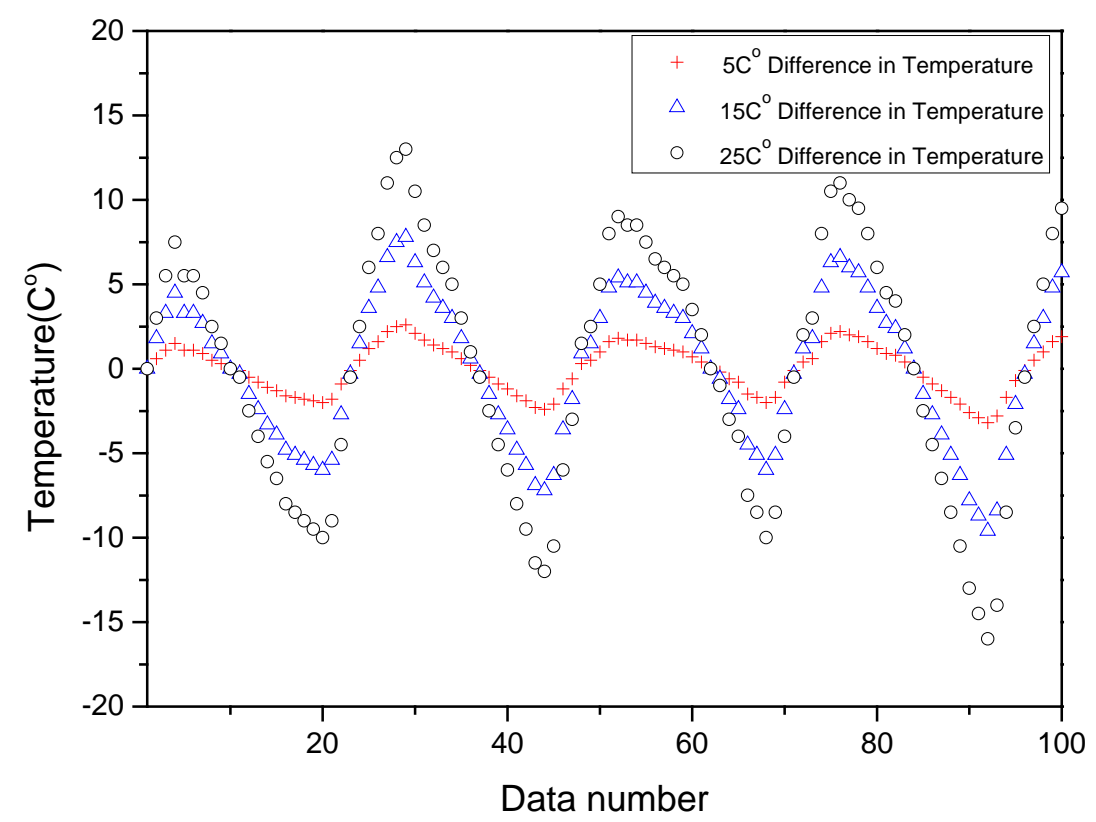

Figure 9 Three different temperature curves

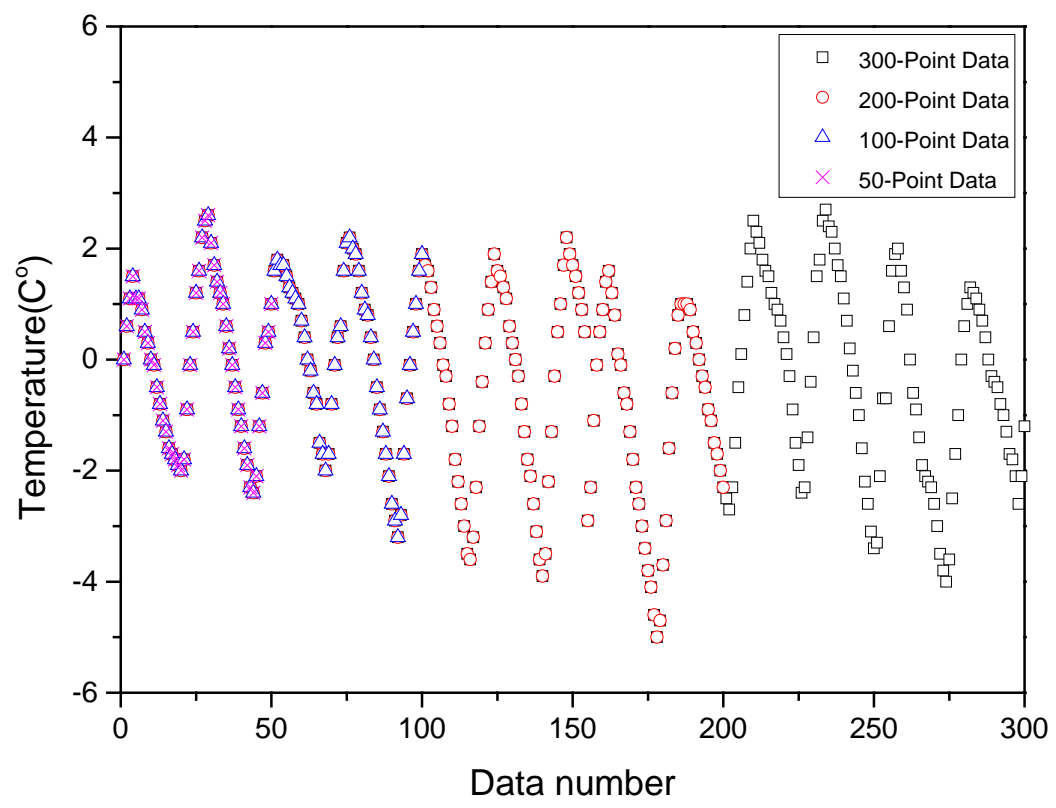

Figure 10 Four different temperature data lengths 


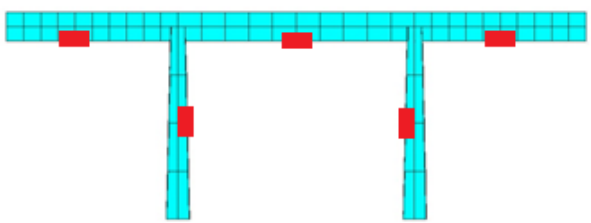

Scenario I

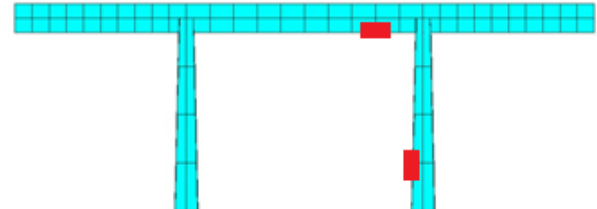

Scenario III

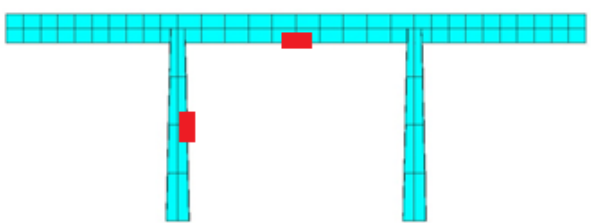

Scenario II

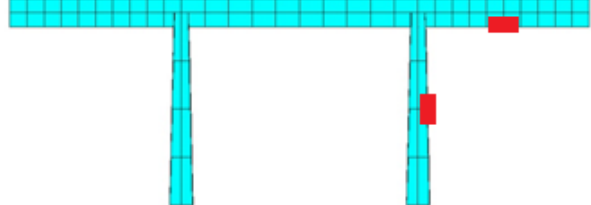

Scenario IV

Figure 11 Different sensor arrangements

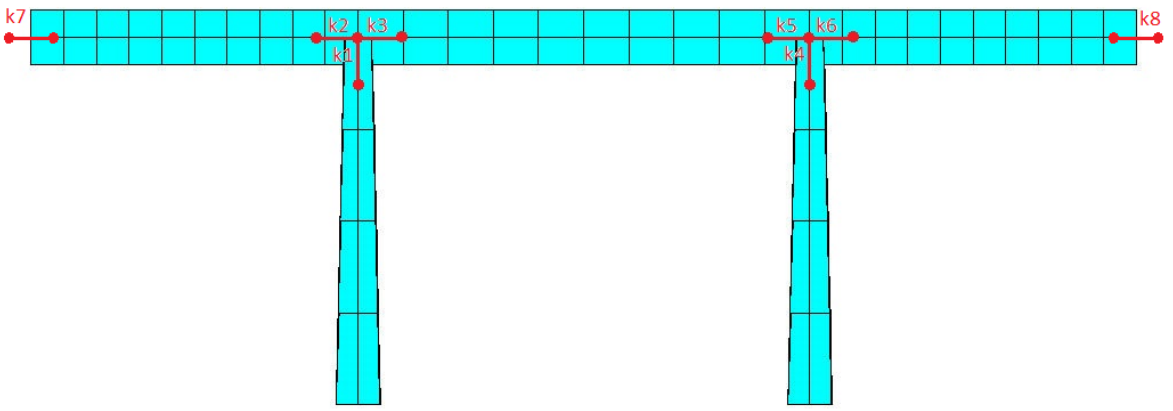

Figure 12 Finite element model considering unknown boundary conditions 


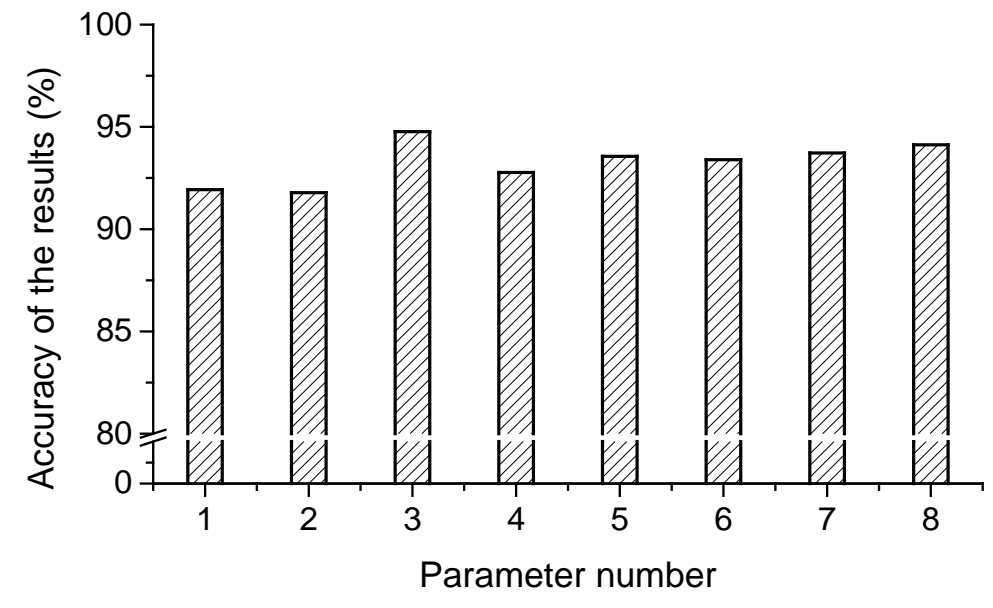

Figure 13 Parameter identification results considering unknown boundary conditions

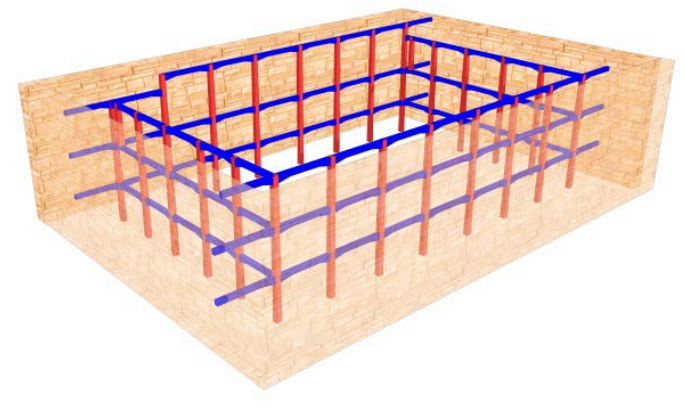

Figure 14 The traditional Chinese timber building

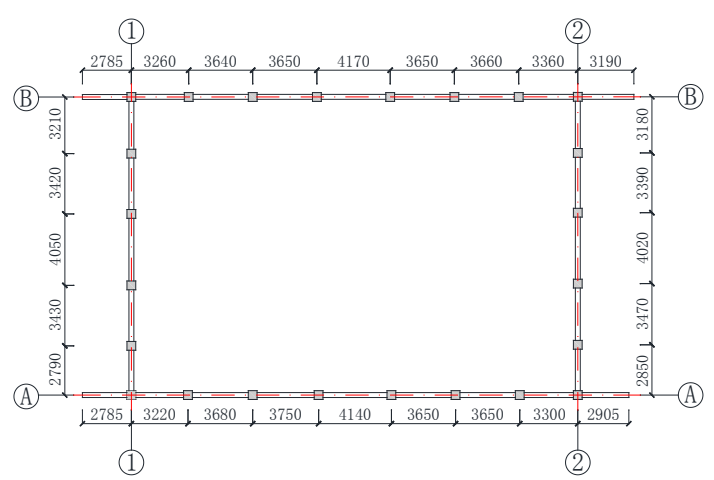

Figure 15 Floor plan for the three-storey wooden frame

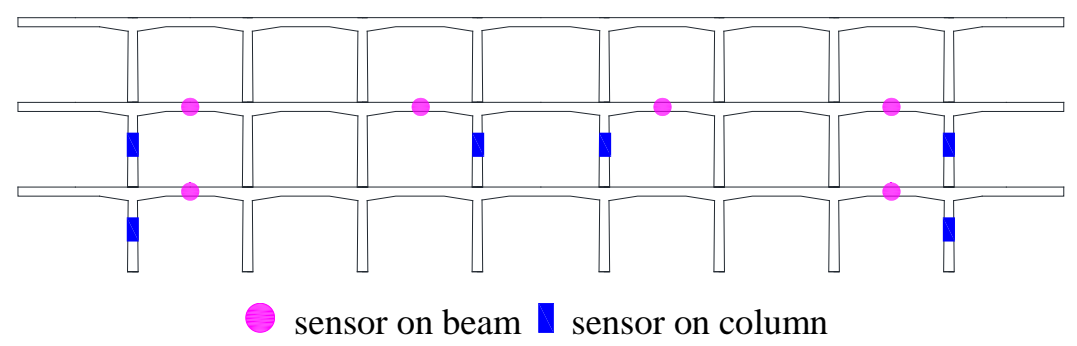

Figure 16 The frame model and sensor arrangement 


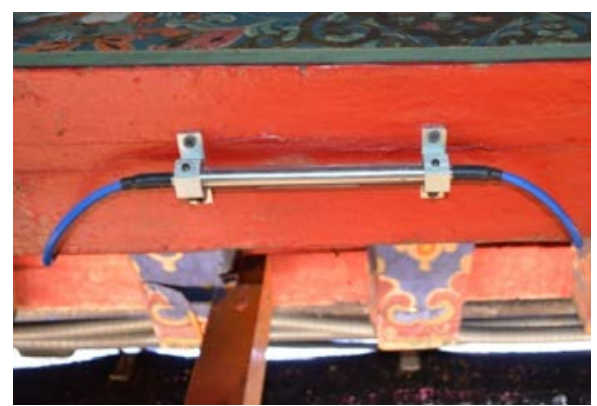

Figure 17 The Fiber Bragg grating strain gauge

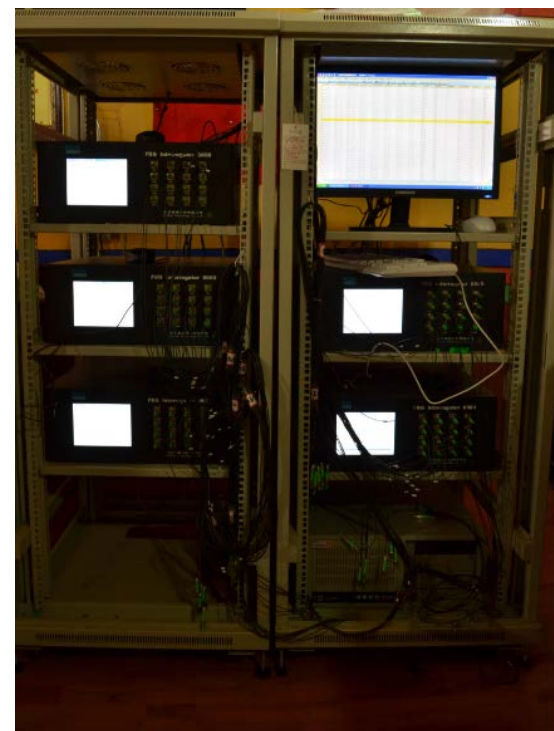

Figure 18 The data acquisition system

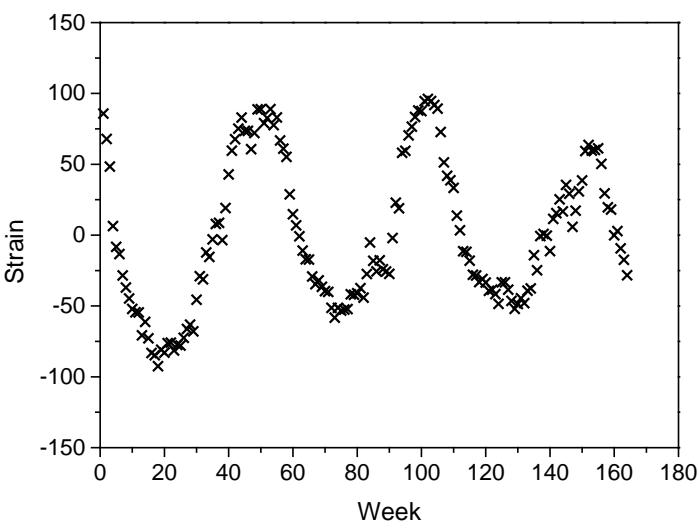

(a) Strain time history

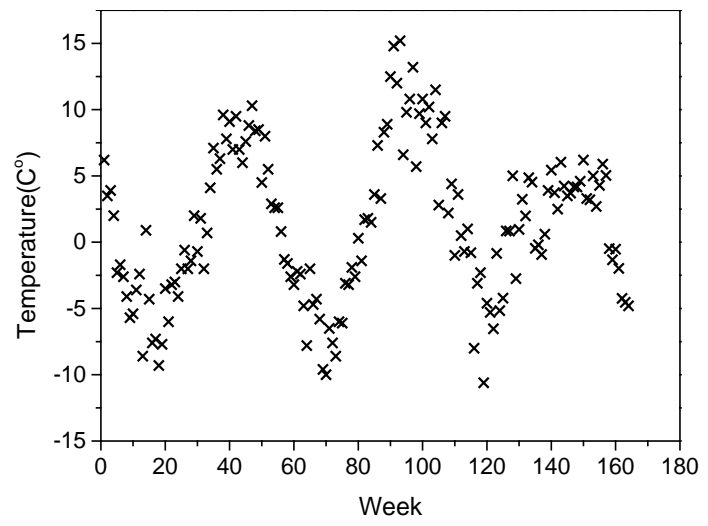

(b) Temperature changes

Figure 19 Data from Fiber Bragg grating strain gauges

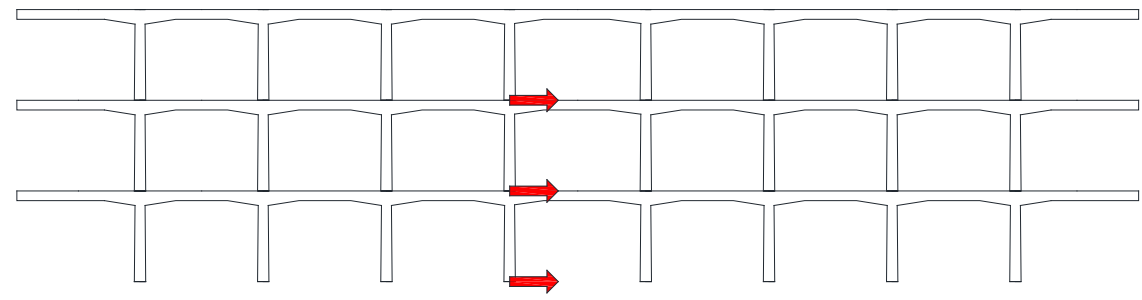

Figure 20 The frame with accelerometers 


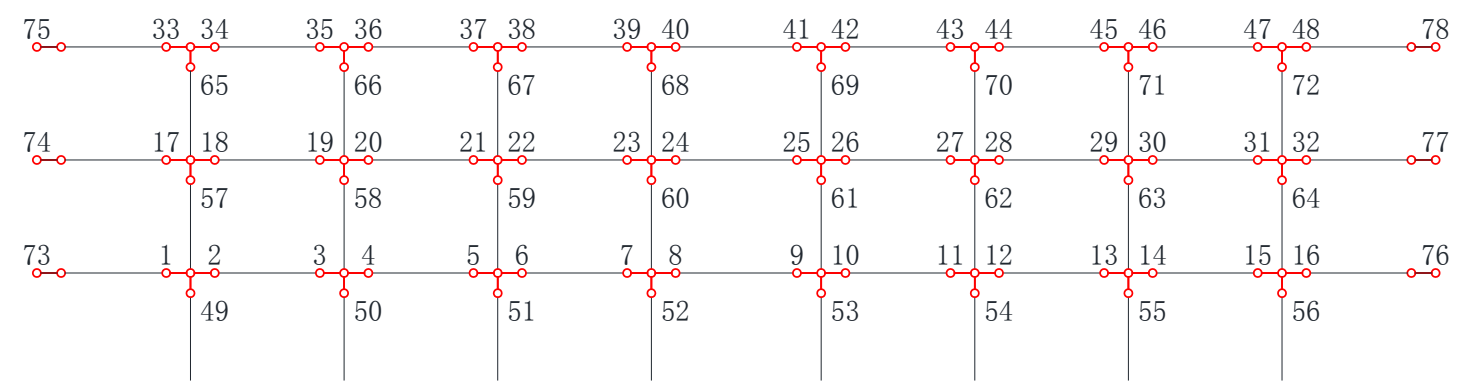

Figure 21 The frame structure with the spring element number

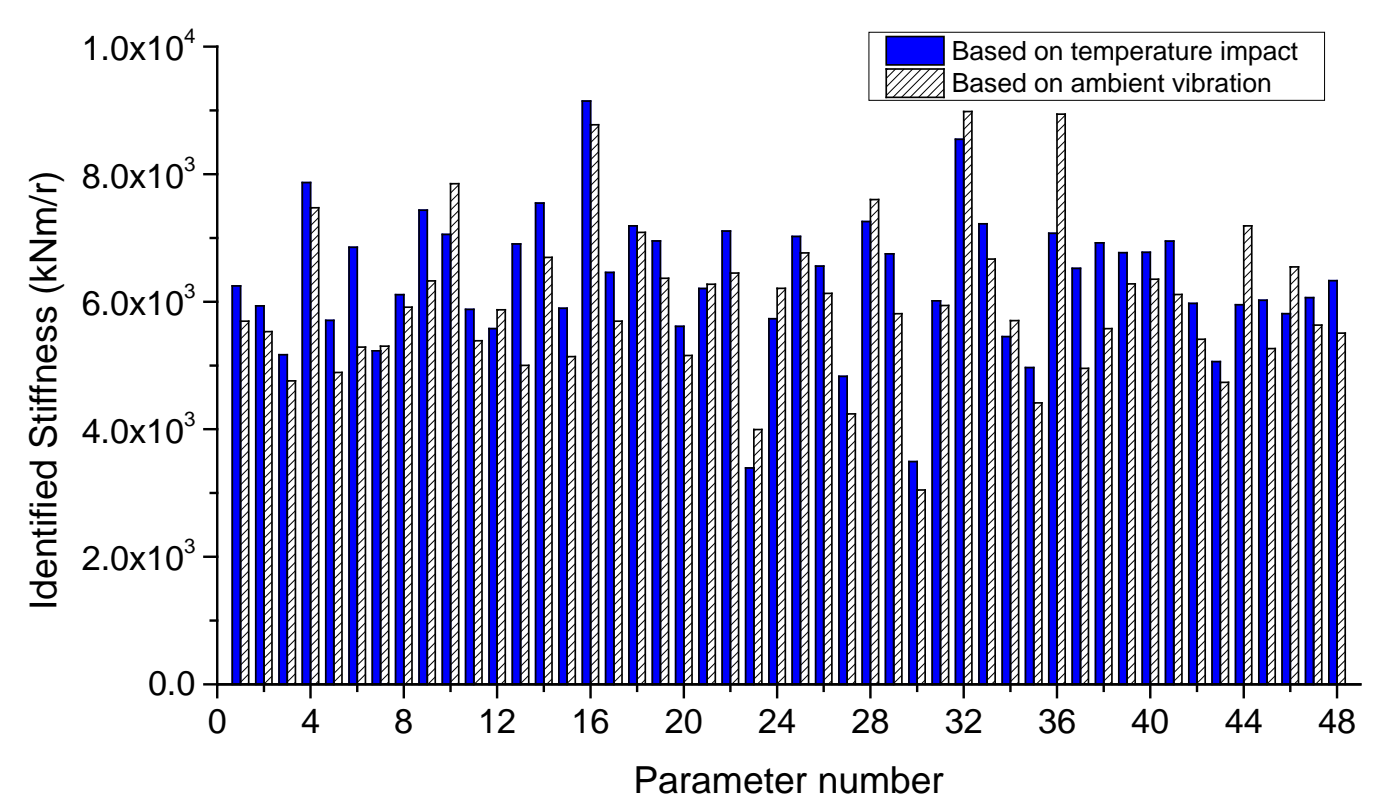

Figure 22 The identified stiffness results of rotational spring elements 


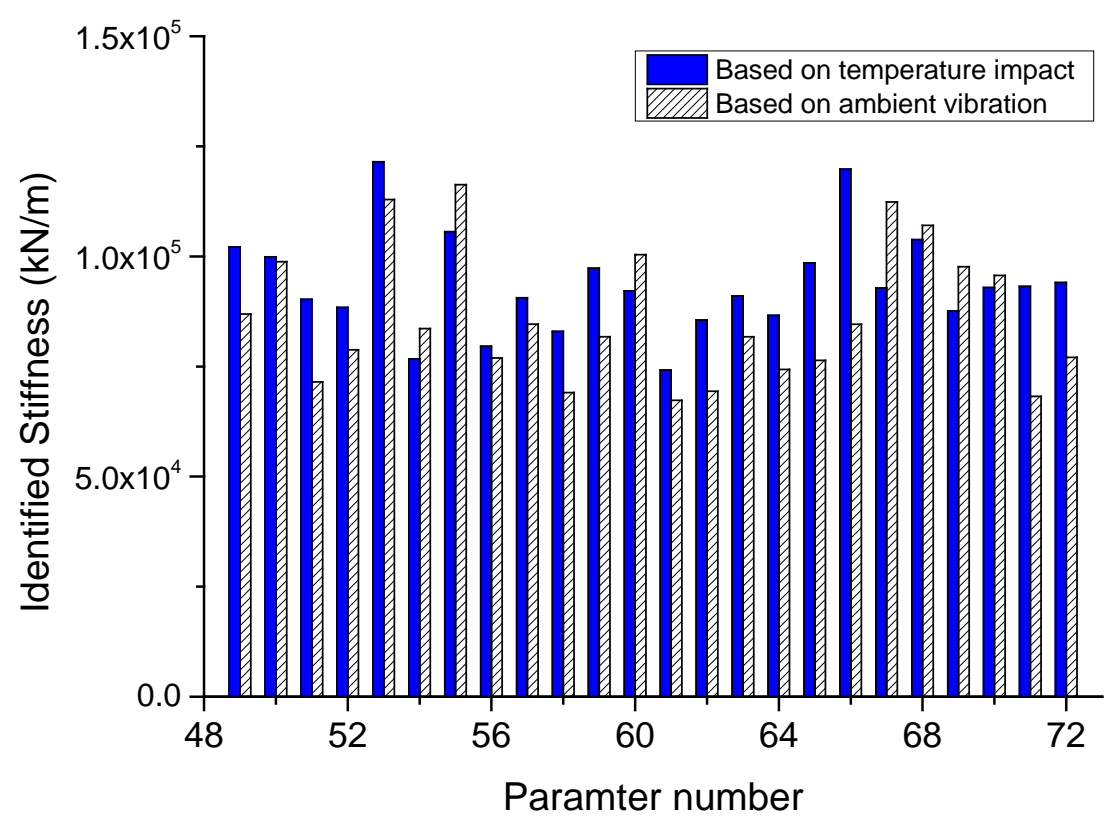

Figure 23 The identified stiffness results of vertical spring elements

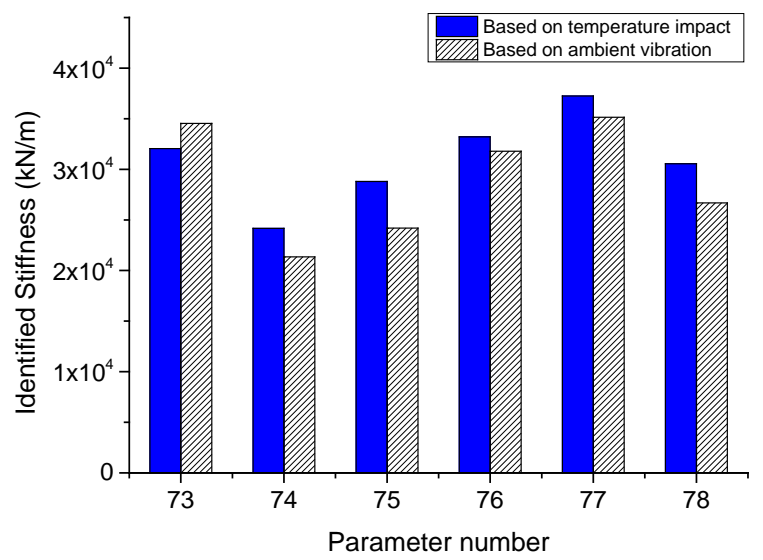

Figure 24 The identified stiffness results of longitudinal spring elements 


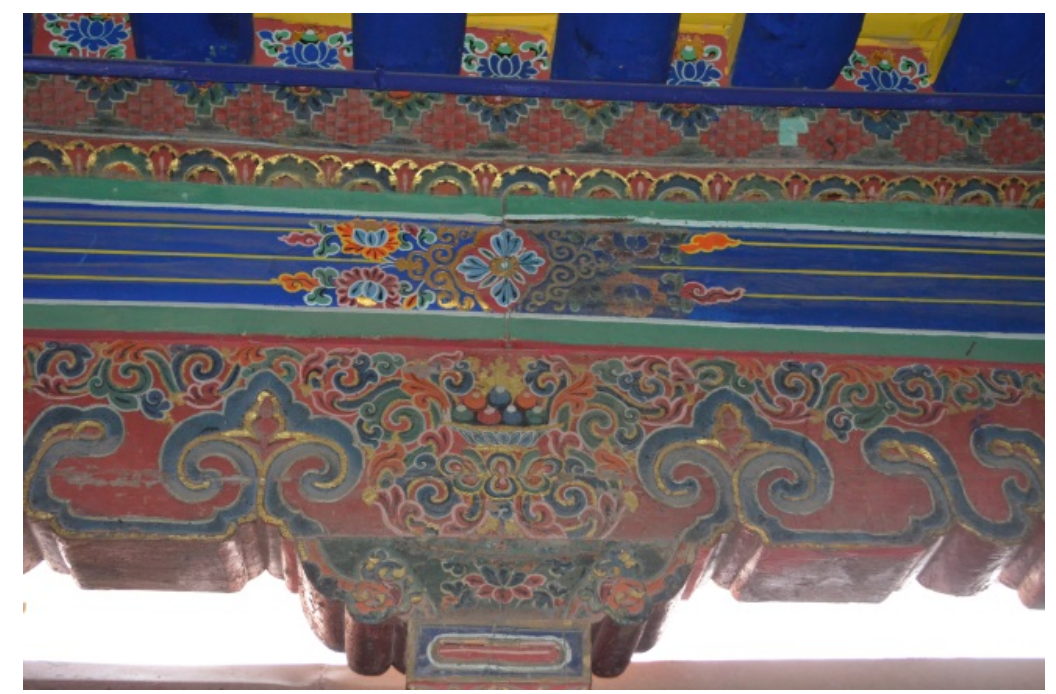

(a) The 'Que-Ti' for torsional stiffness elements 27 and 28

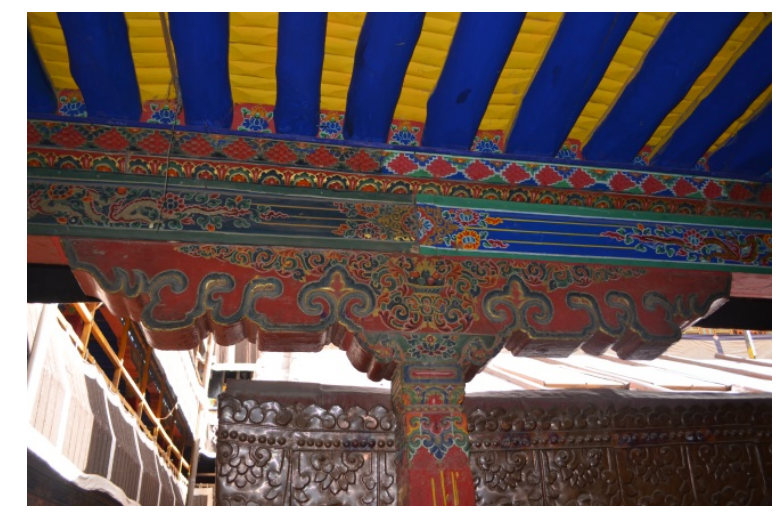

(b) The 'Que-Ti' with the largest compressive stiffness

Figure 25 The two connections with damage in the right connection 